\title{
Involving Everyone: Coding and Decoding Languages
}

\author{
Therese Keane \\ Department of Education, Swinburne University of Technology, Australia \\ tkeane@swin.edu.au \\ Monica Williams \\ Association of Independent Schools of South Australia, Australia \\ williamsm@ais.sa.edu.au \\ Christina Chalmers \\ Faculty of Education, Queensland University of Technology, Australia \\ c.chalmers@qut.edu.au \\ Marie Boden \\ School of IT and Electrical Engineering, University of Queensland, Australia \\ marieb@itee.uq.edu.au
}

\begin{abstract}
Through the use of humanoid robots, a rural school in South Australia has included both Aboriginal and non-Aboriginal people in embedding the "sleeping" language of the traditional owners of the land (the Narungga people) into the classroom. Aboriginal and non-Aboriginal students worked with virtual and real humanoid robots to develop in parallel both their programming skills and their understanding of the Narungga language and culture. This research is part of a larger three-year study investigating the impact of humanoid robots on students' learning and engagement and draws on questionnaires, interviews and journals from the educators. The study demonstrated how pride and interest in Aboriginal culture can be partially reclaimed using these inclusive and adaptive technologies. Simultaneously, students and educators were learning two languages; the coding language required to program the robot and the Narungga language.
\end{abstract}

Keywords. Programming, humanoid robots, Aboriginal students, language and culture

\section{Introduction}

Humanoid robots and programming were introduced to a rural school in South Australia with the intention to use technology to connect students with the local indigenous culture. Historically, the Australian Aboriginal and Torres Strait Islander people have been alienated from their traditional culture, firstly as a result of British colonial practices in the nineteenth century and then subsequent Australian Government policies. Post-colonisation, most of the 350 Aboriginal and Torres Strait Islander nations were forced from their lands and Government policies made it 
difficult to engage with their language and culture. Almost two centuries later, Aboriginal children on the Yorke Peninsula know little about the culture of their people and do not speak or know their Aboriginal language. With limited knowledge of their cultural identity and a traumatic post-colonial history, students do not have a pride in their Aboriginal identity that is befitting of the children, of one of the oldest living cultures in the world.

The Kindergarten - Year 9 school in this study has 240 students, 22\% are Aboriginal students. The traditional owners of the Yorke Peninsula are the Narungga people and many of the students at the school in this study have Narungga heritage. The school acknowledged the injustice that has been done to the Aboriginal peoples and wanted to find a way to work in a partnership with the local Aboriginal community to reconnect these students to their heritage. For six years, dictionaries for the Narungga language laid unused at the school. What brought the dictionaries to life was the integration with digital technologies, through the use of humanoid robots and through the authentic learning of the Narungga language.

This research project reconnected the Aboriginal students, and non-Aboriginal students, with the language and culture of the traditional owners of the land on which the school was built. With the vision of the principal and three educators, this rural school involved their local community in using adaptive technology to build deeper understanding and respect between communities. By working in partnership with the local Aboriginal community and the one fluent speaker, the school re-invigorated interest in the language, which had been dormant for generations. The learning that happened in the school was a result of a unique partnership between the Association of Independent Schools of South Australia (AISSA), the school, and the local Aboriginal community. The educators, students, and the AISSA shared their learning of two languages; the local Aboriginal language of Narungga and digital programming, with their wider communities.

\section{Literature review}

The interest in educational robotics has seen its popularity grow [1, 2]. For over a quarter of a century, many initiatives, courses and competitions have been developed in the context of educational robotics, however the introduction of humanoid robots is relatively new to schools. More needs to be known about how humanoid robots can have a positive impact on students' learning and motivation [3].

It has been argued that educational robots are one of the best problem-solving tools to assist students develop knowledge and skills required for the 21st century $[4,5]$. Asking questions, working together, problem solving, and thinking critically and creativity are seen as essential for the 21st century. These 21st century skills, also known as the 4Cs, have been identified as critical thinking, collaboration. communication, and creativity [6-8]. Keane, Keane, and Blicblau stated that appropriate situations need to be created to allow students to develop a mastery of the 4Cs. Students can engage in critical thinking with robots by investigating problems [9].

The use of humanoid robotics affords an environment where students can solve real life problems or conduct experiments, based on their interests, and their skill 
level. This type of environment according to Alimisis [10] engages "students' curiosity and initiate motivation." Students are more likely to persevere with problems whilst engaged in robotics activities that require them to analyze and synthesize and come up with new and creative ways to find solutions, collaborate with their peers, and communicate their learning. Other uses of educational robotics such as the telling of stories, can be considered an alternative pathway to engaging with educational robots [11].

The humanoid robot used in schools are pre-assembled and take the shape of a human form with two arms, two legs, a body and a head. The robot sensors and movements emulate human interactions, such as sight, sound, touch and social behaviours which can be programmed through drag and drop software or through Python code.

In this study, humanoid robots and programming were introduced to students in a rural school with the intention to use technology to reconnect students with their Indigenous language and culture. Robots can act as a bridge in enabling students to understand humans [12]; and in this study, to understand the Narungga language and culture. Thorpe and Galassi [13] believed that digital technologies have been an enabler for Indigenous people by providing a means for their cultural heritage to be "digitally returned and brought together for community use." Technologies, embedded in culturally responsive pedagogies that link the Aboriginal home culture and school culture, have been shown to improve engagement and learning within Indigenous students in STEM subjects [14]. In this case study where students are learning to program a humanoid robot, they are developing 21st century skills within a framework of Indigenous interests, cultures and languages, and strengthening the connection between school, home and country.

\section{Background information about the project}

The Association of Independent Schools South Australia (AISSA) purchased two NAO humanoid robots (Pink \& Thomas) to use in independent schools in South Australia. For three years, the AISSA regularly invited all of its 96 member schools to submit a proposal outlining how the school intended to incorporate the robot into student learning. Interested principals approached educators and together they forwarded an expression of interest to participate in the study. The AISSA allocated the robots to successful schools for a period of time ranging from 8 weeks and up to 6 months. The university researchers were not part of the selection process, and their involvement commenced once the robot had completed its time in a school. Before the humanoid robot was deployed, the AISSA offered two days of professional learning to the participating teacher/s from the school. The professional learning outlined the project aims, emerging themes from the research, and was designed to also support educators to program and code the robot. During the workshops educators were encouraged to consider their pedagogical approaches and data collection that would provide them with insights into students' learning. 


\section{Method}

In this project, a humanoid robot (Pink) was deployed into a rural school in South Australia for a period of six months. This paper (second year of the study), is part of a wider 3-year multiple case study research project that investigates the use of humanoid robots in different school settings. Each school was considered as a separate case study from the perspective of the "qualitative or naturalistic research paradigm" [15]. As the investigation was focused on description and investigation rather than on cause and effect, the research focus was on the impact humanoid robots have on learning and engagement in the classroom. The case study approach was chosen for a number of reasons; it was important to understand what was being done by educators and students, the depth of the student learning, and the classroom context. In this paper, we will be focusing on one school and how they unified difficult, complex, and sensitive issues with technology and programming with the intention of involving everyone at the school and strengthening their community.

\subsection{Sample}

A humanoid robot was deployed for 6 months in a Kindergarten- Year 9 school. The principal and three teaching staff were directly involved in this project. These four educators came from a variety of learning contexts, had varying years of teaching experience and represented a range of learning areas. They also had varying capabilities, attitudes, skills, and confidence with regards to using technology. The four staff at this school wanted to know if the humanoid robot could be a catalyst for offering Aboriginal students a greater sense of pride in their culture and if the technology could create a more inclusive school community, by strengthening relationships and respect between the Aboriginal and non-Aboriginal members. The following table provides a breakdown of the participants:

Table 1. Breakdown of participants

\begin{tabular}{llll}
\hline Name & Year level/Role & $\begin{array}{l}\text { \# Aboriginal } \\
\text { Students }\end{array}$ & $\begin{array}{l}\text { \# Non Aboriginal } \\
\text { Students }\end{array}$ \\
\hline Educator A & Year 1 \& 2 & 6 & 0 \\
Educator B & Year 3 & 2 & 16 \\
Educator C & Year 4 & 9 & 20 \\
Educator D & Principal & 53 & 187 \\
\hline
\end{tabular}

\subsection{Sources of data}

Data collection methods included questionnaire, semi-structured interviews, classroom videos, student work samples and reflective journals.

The questionnaire consisted of 24 questions and was delivered electronically to participants at the conclusion of the robot's deployment. The questionnaire was mainly qualitative in nature and involved a series of open-ended response questions. The questions explored the teachers experience of using the robot in their teaching and their perceptions of student learning. The participants were also asked to identify 
structural and organizational considerations that needed to be addressed when using the humanoid robot.

The reflective journals used in this study provided participants with the means to move beyond focusing on skill development in digital technologies by providing scope for challenging existing beliefs and about pedagogical practices that promote deep student learning [16]; about how their class engaged and interacted with the robot; the benefits for students; and any frustrations and concerns that occurred with the technology. Participants were asked to reflect on the following:

- $\quad$ How do the students in your class engage and interact with the robot?

- How was the robot used in your classroom?

- How has the robot been beneficial for students' understanding of technology?

- Did you have any concerns or frustrations with the technology?

- What suggestions do you have for other teachers trying to integrate humanoid robots with the Australian Curriculum?

- Can you provide samples of activities that you did in your classes and comment on whether these activities were successful or not?

Semi-structured interviewing was used in this study for the purpose of collecting educators' responses for this research. During the interviews, educators were encouraged to discuss their experience working with the humanoid robot in the classroom. These questions were derived from the reflective journal to clarify and further explore information provided by the teachers in their reflective journal.

\section{Data and results}

The collected responses from the educators in this case study were analysed and the results aligned with the 4plus4 Model developed from the emerging themes from the first year of the study [4]. This model was developed by investigating how humanoid robots integrated into the classroom and the common themes that emerged, such as curiosity, challenge, collaboration, communication, critical thinking, creative thinking, computational thinking and coding.

Whilst the 4plus4 Model was created after analysing the data from the first year of case studies, the researchers wanted to know whether this model could be applied to this specific school. Even though, the students were learning to program, which in some respects was no different to other schools the robot was deployed in, this one had complex overlays which made it distinctive. This robotic project was designed to show respect to the Narungga people and provided a vehicle for the school community to appreciate the culture of the traditional owners of the land on which the school sits. The 4plus4 Model highlights how students can achieve success in computational thinking and coding by incorporating the 21st century fluencies; collaboration, communication, critical thinking \& creative thinking (4Cs) and combining their natural curiosity in solving complex challenges. 


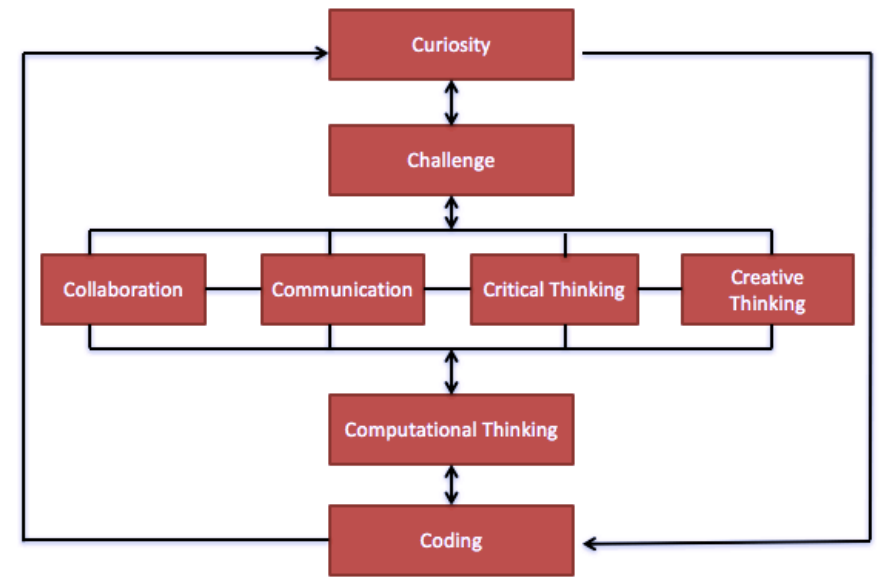

Fig. 1. The 4plus4 Model in Figure 1 identifies eight themes including curiosity, challenge, collaboration, communication, critical thinking, creative thinking, computational thinking and coding.

\subsection{Curiosity}

Curiosity was a pivotal theme evident in both educators and students who engaged with the humanoid robot. Technology must also be easy to use, ubiquitous, linked to real-world problem solving, and involve deep learning. Curiosity incorporates the constructs of interest and engagement and involves students attempting to solve their own questions, suggesting possible relationships and identifying factors that could influence the situation [17].

Curiosity about the humanoid robot was identified by the educators as an important motivational factor that underpinned the acceptance of the robot in the classroom. In this study, it was evident that students were curious when they intentionally sought out additional information to work with the robot so they could explore more advanced programming. Students' interactions with the robots were fueled by the students' curiosity about their new robot friend: the students are driven by a desire to see [the humanoid robot] do 'cool' things. So, they actively try to push the boundaries. Their inquisitive nature and the endless possibilities... with [the humanoid robot] meant that the students should never get bored. [Educator B]

\subsection{Challenge}

Curiosity was enhanced by the complexity of the challenge and this led to further curiosity. The challenge presented a subset of problems which required the students to find a unique solution. For example, when students were learning to program the robot, they needed to firstly learn to speak the Narungga language as well as learn to program the robot using Choregraphe (the proprietary software). They discovered that the robot could not pronounce the Narungga words when they were typed into the 
programming language. Therefore, the students started using the phonetic spelling of the words.

Classroom teachers claimed that deep learning occurred as students began to work on problems that challenged them to think differently. For example, Educator $\mathrm{C}$ provided an example of deep learning in his classroom:

I was thinking about how much deeper the learning has gone, for instance trying to get the language coded into the robot, we played around with recording voice first of all, ...that was not working to well so then we thought, about how else we can do it, and we ended up typing the words in and so we did that first of all and of course they did not pronounce properly. ...then going back to the individual sounds and then decoding how they can reproduce those different sounds using different letter combinations.

Students were highly aspirational in the design their projects and pursued ideas that had higher degrees of difficulty than their teacher had set. Motivated by the challenge, students were engaged in problem solving with the humanoid robot. There was evidence that there were multiple ways students were challenged by the programming activities: the robots provided an opportunity for differentiated, selfdirected learning to take place; the visual programming software (Choregraphe) used to program the humanoid robot provided a range of entry points for students; and the challenge of the complex open-ended learning tasks permitted students to create programs that stretched their intellect while remaining within their zone of proximal development [18].

\subsection{Collaboration, communication, creativity and critical thinking}

The participants identified collaboration, communication, creativity, and critical thinking as four skills their students developed whilst working with the humanoid robot. These skills, grouped together are also known as 21st century skills [5-8, 19]. This study found that both educators and students were able to communicate their ideas and understanding, therefore creating a more collaborative classroom. The educators reported that students engaged with creative and critical thinking whilst they were focused on completing their robot programs. Students were critically evaluating ideas and refining them to accommodate their expanding coding skills to constantly improve the functionality of the humanoid robot.

This was demonstrated in the classroom when students developed their programming ideas into actuality through individual and collaborative problemsolving. As students' ideas and coding skills developed so did their confidence levels and this was evident when they pursued increasingly complex programming concepts and successfully mastered them.

\subsection{Computational thinking}

According to Wing [20], "computational thinking involves solving problems, designing systems, and understanding human behaviour, by drawing on the concepts fundamental to computer science.” Wing [21] proposed that computational thinking would enable students to use abstraction, algorithmic and recursive thinking, patternmatching, and logical thinking in order to solve complex problems. These skills were evident in this study as Educator A stated: 
[There was] lots of problem solving with my group... Working out how to get Pink to say Narungga words correctly and adjusting our spelling to suit, trying different things with object recognition, to try and get it to work, trying to solve problems when getting Pink to touch her knees.

The educators identified a number of skills that students adopted related to computational thinking including: problem decomposition, algorithmic thinking, problem solving, and testing and debugging. Using the computational thinking skills students were able to use the humanoid robot to develop new ways of thinking about problems, particularly in relation to how to use the robot's software and hardware to embed the Narungga language and culture. The students represented their solutions as computational steps and algorithms.

\subsection{Coding/programming}

The educators in the study reported that the humanoid robot sparked students' interest in coding and robotics. The students' curiosity in engaging with the humanoid robot extended to using the humanoid robot's drag and drop programming software. The students programmed the robot using its proprietary software (Choregraphe) loaded onto a computer. Once the students completed the coding sequence on the computer, the program was then uploaded to the robot. Students in Year 1 and 2 programmed visual recognition and facial recognition movements and the Year 4 students synchronised the robot's movements and actions, through programming. Teacher A remarked on how quickly her Year 1 and 2 students embraced coding the robot.

As the students' confidence in engaging with the robot increased, they tried more complex programming and were more willing to take risks. Students further developed their coding skills as they experimented with the programming software.

The educators in this school recognised the importance of coding and robotics for their students' future and the far-reaching opportunities to integrate this technology in ways that build respect and understanding between cultures:

This has not only engaged our students; it has engaged our staff as well. It

has given them encouragement in what they have seen from the students to

keep progressing with the [Narungga] language as well as the digital side of things. [Educator D]

More than anything, this project has confirmed for this school that their vision is to be an innovative school that utilises coding as part of the inclusive and adaptive technologies to connect in authentic ways with their Aboriginal and non- Aboriginal communities.

\section{Discussion and conclusion}

This research paper is part of a larger three-year study investigating the impact that humanoid robots have on student learning and engagement. It was apparent from the four educator's perspectives, that the students were deeply engaged with learning about the local Aboriginal language and culture through the use of a humanoid robot. What is intriguing about this case study, is that the complexity, the authenticity, and the purpose created a conducive and accepting environment whereby the students were learning the language and culture of the Narungga people - the traditional 
owners of the land. The students were learning the language and culture of a dormant and sleeping language, whilst simultaneously learning a programming language by communicating instructions to a humanoid robot.

Both languages, (Narungga and the programming language) were unfamiliar to students and the educators. It was considered a steep learning curve to learn and understand two different ways of communicating - both old and new, however, the school was determined to ensure the involvement of the wider community, the educators, and students. There was considerable trust shown by all involved, to be able to breathe new life into a dormant language using cutting-edge technology, was a precarious project that was considered successful by the principal and the educators involved. The Aboriginal and non-Aboriginal students who participated in the study had a reported new sense of pride in the language of the traditional owners of the land and significantly, the success of this project was dependent upon the support of the local Aboriginal community, in particular the Narungga people.

While our findings confirm previous research that robotics technology engaged students in learning, the use of humanoid robots in the classroom has been recent. Using the 4plus4 Model to analyse the data collected highlighted how humanoid robots can develop 21st century skills of creativity, critical thinking, communication, and collaboration along with coding and computational thinking skills. Curiosity was also evident due to the engaging nature of the technology. This curiosity was enhanced by the challenge of solving complex open-ended learning tasks. Students were able to achieve success with coding by using computational thinking skills. The students developed a deeper understanding of coding as they experimented with the software engaging in real-world tasks that re-invigorated a 'sleeping' Aboriginal language. Educators reported that the complexity and sophistication of computational thinking and coding surpassed their expectations and made them see their Aboriginal and non-Aboriginal students in new and different ways. This finding challenges not only long held assumptions about students and their learning potential, but also the pedagogy, the very beliefs that educators have about their learners in the area of digital technologies, and the strategies and methodologies that promote deep learning.

\section{References}

1. Alimisis, D.: Educational robotics: Open questions and new challenges. Themes in Science and Technology Education. 6(1), 63-71 (2013)

2. Somyürek, S.: An effective educational tool: Construction kits for fun and meaningful learning. International Journal of Technology and Design Education. 25(1), 25-41 (2015)

3. Chang, C.-W., Lee, J.-H., Chao, P.-Y., Wang, C.-Y., Chen, G.-D.: Exploring the possibility of using humanoid robots as instructional tools for teaching a second language in primary school. Educational Technology \& Society. 13(2), 13-24 (2010)

4. Keane, T., Chalmers, C., Williams, M., Boden, M.: The impact of humanoid robots on students' computational thinking. In: Australian Computers in Education Conference 2016, pp. 93-103. (2016)

5. Eguchi, A.: What is Educational Robotics? Theories behind it and practical implementation. In: Society for Information Technology \& Teacher Education International Conference, pp. 4006-4014. AACE, (2010) 
6. University of Melbourne, http://atc21s.org/index.php/about/what-are-21st-centuryskills/

7. Keane, T., Keane, W.F., Blicblau, A.S.: Beyond traditional literacy: Learning and transformative practices using ICT. Education and Information Technologies. 21(4), 769-781 (2016)

8. MCEETYA: Melbourne Declaration on Educational Goals for Young Australians. Curriculum Corporation. (2008)

9. Savard, A., Freiman, V.: Investigating complexity to assess student learning from a robotics-based task. Digital Experiences in Mathematics Education. 2(2), 93-114 (2016)

10. Alimisis, D.: Robotics in education \& education in robotics: Shifting focus from technology to pedagogy. In: Proceedings of the 3rd International Conference on Robotics in Education, pp. 7-14. (2012)

11. Rusk, N., Resnick, M., Berg, R., Pezalla-Granlund, M.: New pathways into robotics: Strategies for broadening participation. Journal of Science Education and Technology. 17(1), 59-69 (2008)

12. Mubin, O., Stevens, C.J., Shahid, S., Al Mahmud, A., Dong, J.-J.: A review of the applicability of robots in education. Journal of Technology in Education and Learning. (1), 1-7 (2013)

13. Thorpe, K., Galassi, M.: Rediscovering Indigenous languages: The role and impact of libraries and archives in cultural revitalisation. Australian Academic \& Research Libraries. 45(2), 81-100 (2014)

14. McKinley, E.: STEM and Indigenous students. Research Conference 2016 Improving STEM Learning - What will it take? pp. 64-68. Australian Council for Educational Research, Brisbane Convention and Exhibition Centre (2016)

15. Merriam, S.B.: Case study research in education. Jossey-Bass, San Francisco, USA (1988)

16. Koszalka, T.A.: Reflection as a critical component of the technology adoption process. ERIC Document Reproduction Services ED 480, 237 (2003)

17. Arnone, M.P., Small, R.V., Chauncey, S.A., McKenna, H.P.: Curiosity, interest and engagement in technology-pervasive learning environments: A new research agenda. Educational Technology Research and Development. 59(2), 181-198 (2011)

18. Vygotsky, L.: Thought and language. MIT Press, published originally in Russian in 1934, Cambridge, MA (1962)

19. http://www.amanet.org/organizations/2010-survey-critical-skills.aspx

20. Wing, J.M.: Computational thinking and thinking about computing. Philosophical Transactions of the Royal Society of London A: Mathematical, Physical and Engineering Sciences. 366(18881), 3717-3725 (2008)

21. Wing, J.M.: Computational thinking. Communications of the ACM. 49(3), 33-35 (2006) 